\title{
NEW LABORATORIES FOR INORGANIC AND PHYSICAL CHEMISTRY IN THE UNIVERSITY OF LIVERPOOL
}

$\mathrm{T}$

HE new Laboratories of Inorganic and Physical Chemistry in the University of Liverpool were opened by H.R.H. the Duke of Edinburgh on May 11 . The building is one of the first to be completed according to the plan and in the area set aside for the development of the University. The laboratories, of a total floor area of 88,000 sq. ft., provide for the teaching of both inorganic and physical chemistry at the various levels of training required for students specializing in chemistry and for those students who study chemistry as a preparation for specialization in medicine, dentistry, veterinary science, engineering and metallurgy. The laboratories provide places for some four hundred undergraduates at any one time, and for forty to fifty research workers.

The building (Fig. 1) comprises two large wings, each of two stories, with a connecting spine of three stories from pavement-level. The latter contains specialized laboratories and research, staff and cloak rooms. In each of the wings are located two large laboratories one above the other for undergraduate teaching. Each laboratory is serviced by a sub-store connected to the main store by a goods lift, and has a balance room and fume room attached. In addition, there are rooms for special teaching purposes. The basement, which extends throughout the wings and the spine, houses the main stores, workshops, glassblowing, electronic and photographic rooms, and the air-conditioning, heating, liquid nitrogen and electrical plant. The main stores and the separate underground acid and solvents stores are served from ground-level by a goods lift situated in the small extension adjoining the side entrance to the laboratory.

The design of the building is essentially functional. It is built with a steel frame, the walls being of cavity brickwork with specially selected facing brick. The structural floors are of reinforced concrete, and air-conditioning ducts are carried in the space between floor and ceiling.

Floors in all laboratories and staff rooms are finished with narrow strip African mahogany (karuin) boards. The corridor on the ground floor, stair treads, and stair landings and halls are floored with terrazzo tiles. Walls and ceiling are plastered and protected by acid-proof paint.

The heating of the building is by low-pressure hot water, within invisible ceiling panels. The boilers are oil-fired, the heating system being operated in conjunction with the air-conditioning plant, and all rooms are thermostatically controlled.

In addition to the normal a.c. electricity supply, d.c. is available from fixed and mobile rectifier units. Lighting is by tungsten lamps, except in the basement rooms and corridors, where fluorescent strip is used.

The building was constructed on the general principle that all service pipes were to be accessible, and that fixed horizontal drains either in or under the floors were to be avoided. The main pipes and conduits carrying the services, which include gas, hot and cold water, compressed air, distilled water and electricity, and also the heating mains, are slung at ceiling-level along the full length of the basement trolley-way. Branch mains from the main service pipes are run vertically in the service ducts, and the smaller horizontal branches which service individual benches are concealed behind removable polished plywood panels.

The avoidance of fioor drains meant a change from the traditional type of 'island' laboratory bench to the 'peninsular' type. All horizontal wastes are within the bench casing above floor-level and discharge

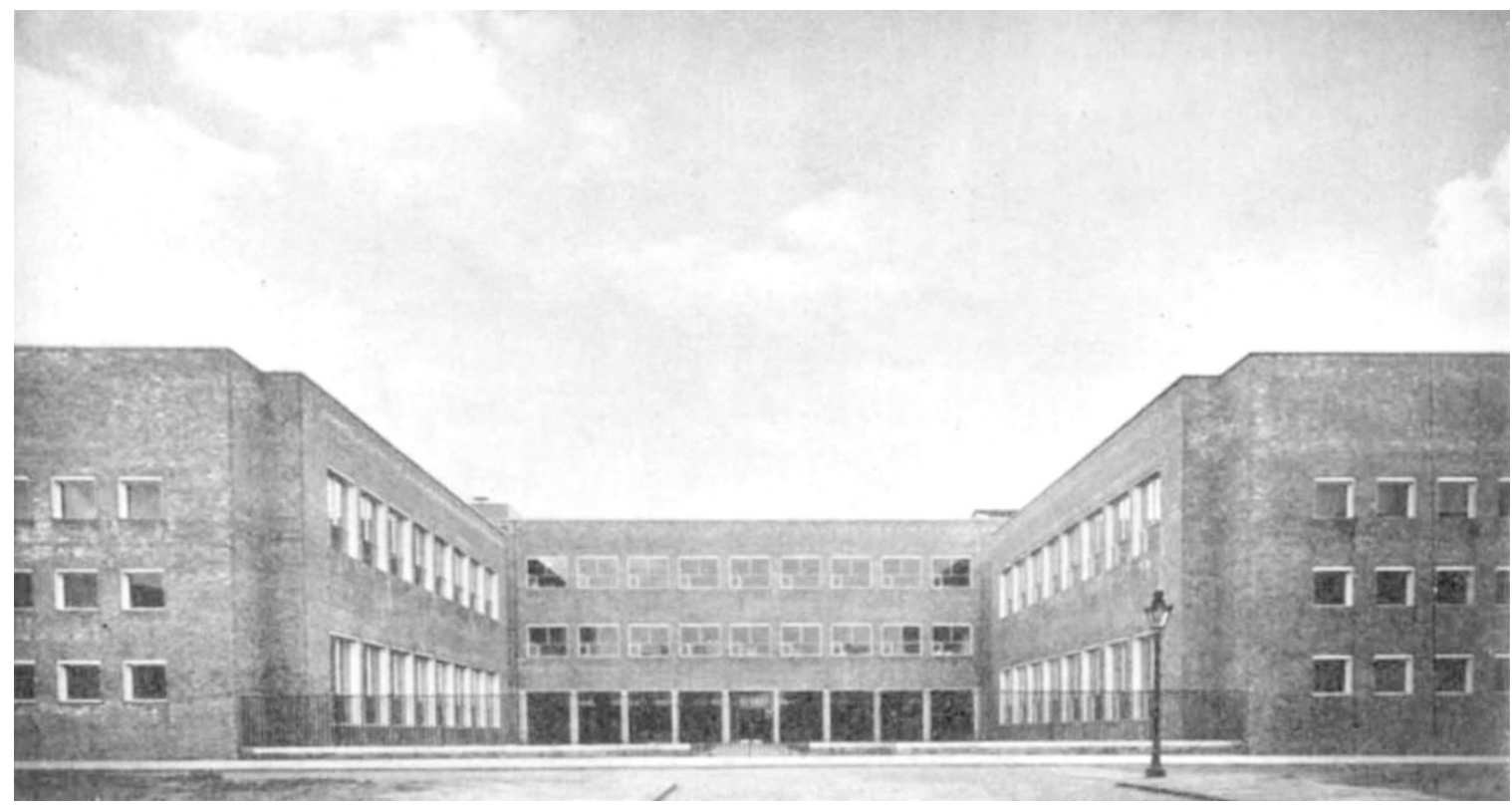

Fig. 1. Front view of Inorganic and Physical Chemistry Laboratories, University of Liverpool 
directly into the catchpot, which in turn discharges into a vertical drain stack. The vertical acid-drain stacks occur at $10-\mathrm{ft}$. intervals, that is, at every steel stanchion between windows and on the centre lines of laboratory benches.

Service pipes to these benches branch off the lines under the window benches, the water, compressedair pipes and electricity conduits running under the reagent shelf spaced at $15 \mathrm{in}$. above bench-level, while the gas tubing is taken alongside the waste trough under the bench top. Only gas controls are on the bench top, and these are raised above benchlevel to reduce corrosion and to ease cleaning and polishing of the benches. Removal waste bins are an integral part of the bench design.

Polythene ('Vulcathene') has been used for lining the central waste troughs in the benches and the waste pipes from benches, drip sockets and sink traps in all laboratories. The latter, being precision made and thus identical, are readily interchangeable and saved much time and labour in the construction and erection of the benches. The bench tops are constructed of seasoned African teak, and alternate laboratory benches are fitted with a glazed sink or a readily removable inset so that a standard thermostat projecting $9 \mathrm{in}$. above the bench-level can be inserted. Water, gas and general fittings to the bench are of gun metal.

In all teaching and research laboratories, foul air is extracted at both floor- and ceiling-levels.

Fume cupboards in the teaching laboratories are in a special fume room at one end of the laboratory. The controls for the service points are external and mounted on a black plastic panel under the cupboard working surface. Each fume cupboard is lighted by fluorescent tube fixed above the working surface, and protected from fumes by a removable sheet of obscured glass. Fumes are extracted from the cupboards through high- and low-level outlets in the rear walls by exhaust motors situated in the roof of the building and individually controlled.

The research laboratories have not been individually designed for specialized work, the services and layout being sufficiently flexible for the laboratory to be adapted to any type of chemical research work. Only a few of the laboratories have fixed benches, and in general the normal services have been made available from a 9-in. shelf attached to the wall at $3 \mathrm{ft}$. above the floor. This arrangement permits full use of space. Soft-wood tables (or metal frames where necessary) of various heights and designs are used for the erection of apparatus. Additional equip. ment in research rooms are wall channelling, and floor- and ceiling-tapped sockets which may be used for the attachment of blackboard, shelves, electrical apparatus and small-diameter 'scaffolding' for supporting a metal framework. The wall channelling is of a $C$ cross-section, so that threaded bolts can be slid along to any position horizontally, the head of the bolt being in the channel and the threaded shank projecting outwards. The floor sockets are directly below those in the ceiling, and all are at 3 -ft. centres, in both directions.

It is proposed to complete the present building within the next two years by the addition of a lecture theatre block comprising three lecture theatres seating 300, 150 and 100 , respectively. This block will also house the library and small seminar rooms, and will form a third wing to the main spine. The spine will also be extended to accommodate the newly created Sub-department of Radiochemistry.

\section{HARWELL MEETING OF THE PHYSICAL SOCIETY}

HE spring meeting of the Physical Society was held at the Atomic Energy Research Establishment, Harwell, during March 31-April 2; the first day was taken up by discussion of topics connected with nuclear energy-levels, the second with topics connected with neutron physics, and there was a visit to the Harwell laboratories on the morning of April 2. About two hundred and fifty people attended, including several visitors from the Continent of Europe; most of the talks were given by physicists from Harwell and Oxford, the other contributions being from Cambridge and the Imperial College of Science and Technology, London.

The subject of nuclear energy-levels was introduced by B. H. Flowers (Harwell) with a review of the theory of the low-lying levels of nuclei. He directed attention to the contrast between the independent particle (the 'quasi-atomic') model of the nucleus, the chief success of which lies in light nuclei; and the collective, or 'quasi-molecular' model, which has accounted for many of the properties of heavy nuclei. In the first model, one takes a central core with one or more external particles, and considers the interactions between the particles and between the particles and the core. The interaction is usually taken, at one extreme, as pure spin-orbit ( $j-j$ coupling) or, at the other extreme, as a force derived from a central two-body potential ( $L-S$ coupling). Alternatively, a mixture of the two interactions (intermediate coupling) has been used with success, as Lane has shown with reference to the lithium isotopes and the mirror nuclei carbon-13 and nitrogen-13. Dr. Flowers suggested that experimental evidence should be sought for the odd-parity levels of nuclei between oxygen and calcium; near oxygen these levels probably correspond to $1 p$ particles being raised to the $2 s$ or $1 d$ shells, and near calcium to $1 d$ or $2 s$ particles being raised to the $2 p$ or $1 f$ shells. $\mathrm{He}$ said that the sequence of spins of these odd-parity levels in oxygen-17 has been observed, by comparison with fluorine-17, to be $1 / 2,7 / 2$ and $3 / 2$, as expected; and that he would expect the corresponding sequence of spins for calcium to be $7 / 2,3 / 2$ and $1 / 2$. For aluminium-25, intermediate between oxygen and calcium, he would expect an intermediate order, as has been found to be the case. Further theoretical evidence for the validity of intermediate coupling in nuclei with atomic masses between 18 and 20 was later presented by J. P. Elliott (Harwell); many of the experimental data can be fitted with a single value of the coupling parameter, and, in particular for fluorine-19, the energies of the lower even-parity levels, the probability of transitions between these levels, and the $\log f t$ values for oxygen-19 and neon-19 decay, can all be accounted for. Experimental evidence for the transition probabilities from the first four levels in fluorine-19, as determined by the gammarays from fast-neutron inelastic scattering, was presented by J. M. Freeman (Harwell) : the levels were established both by the gamma-ray energies and from excitation functions. In addition to wellestablished levels, there was good evidence for a level at $\mathbf{1} \cdot \mathbf{4 3} \mathrm{MeV}$., probably of negative parity. G. Deamaley (Cambridge) showed results of interesting interference effects which occur when protons or alpha-particles are scattered by fluorine nuclei : the 